\title{
A MAGIA DA ESCOLA NA ESCOLA DA MAGIA: A ESCOLA QUE SE INSCREVE NAS HISTÓRIAS SOBRE HARRY POTTER
}

\author{
Maria Lúcia Castagna Wortmann*
}

RESUMO: Neste texto, apresentam-se posições enunciadas por educadores e analistas da cultura sobre a escola e examina-se a sua configuração nas histórias de J. K. Rowling sobre Harry Potter. As análises inspiram-se nos Estudos Culturais em sua articulação com a Educação, considerando-se atuarem as histórias como pedagogias culturais. Destacam-se seus efeitos produtivos no cinema, na web, na comercialização de produtos diversos e na academia e atenta-se para seu papel na configuração discursiva da escola e dos sujeitos que a frequentam. Tais efeitos ultrapassam a dimensão do entretenimento dos nem sempre jovens leitores/consumidores dos textos e artefatos delas originados ou seu sucesso mercadológico! A escola ganha centralidade nessas histórias que narram lutas entre personagens do bem e forças do mal e nelas (re)afirma-se a sua importância, excelência e competência para a formação sistemática de jovens (em magia) e para a apropriação e o desenvolvimento dos saberes e tradições (bruxas).

Palavras-chave: Escola; Pedagogias Culturais; Harry Potter.

\section{SCHOOL MAGIC IN THE MAGICAL SCHOOL:}

\section{THE SCHOOL THAT TEACHES THROUGH STORIES OF HARRY POTTER}

ABSTRACT: In this text we study positions advanced by educators and school observers, and examine how school is shaped in stories J. K. Rowling wrote about Harry Potter. Analyses were inspired by the Cultural Studies in their work with Education, considering that these stories act as cultural pedagogies. We highlight a host of powerful effects in the cinema, the Web, in the marketing of many products, in the Academy, and we focus on the role stories play in the discursive configuration of school and subjects narrated in such stories. We show that their powerful effects go beyond entertainment for not only young readers/consumers of the different texts and artefacts created, but also due to their market success! The school plays an important role in the representations conveyed in these stories, whose main theme is the battle between good and evil. These stories do not raise questions about school; its significance, excellence and power are constantly (re)assured to systematically graduate young magicians and to encourage the appropriation and development of the knowledge and the tradition of witchcraft.

Keywords: School; Cultural Pedagogies; Harry Potter.

\footnotetext{
* Doutora em Educação pela Universidade Federal do Rio Grande do Sul (UFRGS); Professora convidada do Programa de PósGraduação em Educação da Universidade Federal do Rio Grande do Sul (UFRGS) e Professora Adjunta no Programa de PósGraduação da Universidade Luterana do Brasil (ULBRA). E-mail: wortmann@terra.com.br
} 


\section{Introdução}

A discussão sobre o papel da escola na sociedade contemporânea tem transcendido a esfera e o circuito mais restrito da educação - o âmbito das publicações acadêmicas e das discussões conduzidas pelos/as tradicionais agentes da educação (pesquisadores, professores/as, orientadores/as educacionais, gestores/as da educação entre outros/as). Assim, o tema tem inquietado investigadores/as de outros campos do saber, tais como a crítica literária argentina Beatriz Sarlo (2002; 2003) ${ }^{1}$, o filósofo e professor de comunicação, radicado na Colômbia, Jesús Martín Barbero (2002; 2003) e empresários e articulistas de jornais diários brasileiros como Milú Vilela (2007; 2008), diretora do Museu de Arte Moderna de São Paulo, o empresário e coordenador de Artigos e Eventos Uirá Machado (2007) e a psicóloga Rosely Sayão (2007), entre outros sujeitos que, embora não exercendo funções diretamente vinculadas à escola, têm denunciado na mídia a insuficiência das suas ações, ou cobrado do governo, dos políticos e da sociedade civil mais efetividade para a melhoria do ensino brasileiro.

Em outra direção, como salientou Marisa Vorraber Costa (2003), a escola "roubou a cena" de programas humorísticos, sendo $A$ escolinha do professor Raimundo², protagonizado pelo humorista Chico Anísio, na Rede Globo de TV, e $A$ escolinha do barulho ${ }^{3}$, conduzido por Ronald Golias, na TV Record, exemplos bem conhecidos. Mas ela também roubou a cena das novelas - a mesma autora (COSTA, 2003) cita, entre outras, Coração de estudante (2002) e Mulheres apaixonadas (2003), transmitidas pela Rede Globo de TV, e Viva as crianças (2002) e Carinha de anjo (2001/2002), exibidas pelo Sistema Brasileiro de Televisão (SBT) - e de seriados televisivos, sendo Malhaşão, programa endereçado aos jovens, também exibido pela rede Globo de TV, desde 1995, o mais conhecido deles.

Além disso, a escola é tema frequente na literatura. Entre as muitas obras que a focalizam, pode-se indicar, por exemplo, o romance $O$ Ateneu, escrito ao final do século XIX pelo fluminense Raul Pompéia, bem como o clássico da literatura latino-americana $A$ Cidade e os Cachorros, escrito ao final dos anos 1950 pelo peruano Mário Vargas Llosa e lançado em português, em 2007, no qual são destacados os rigorosos códigos de conduta de uma escola militar. Reminiscências da escola também povoam obras de outros escritores consagrados, como as do filósofo 
argelino Albert Camus. Em sua autobiografia O primeiro homem, publicada 35 anos após sua morte 4 , Camus narra como um entusiasmado professor, Monsieur Barnard, era capaz de despertar o interesse e os sonhos dos estudantes em suas aulas. Mas, além dele, outro prêmio Nobel de literatura, o poeta chileno Pablo Neruda, em seu livro autobiográfico Confesso que vivi, escrito em 1974, relatou as muitas sensações de encantamento que a escola lhe despertou aos seis anos de idade.

Cabe apontar, ainda, tal como fez Rosa Maria Silveira (2001), que a escola também é tema recorrente na literatura infanto-juvenil, sendo disso um exemplo recente as histórias escritas pela britânica Joanne Katleen Rowling sobre a vida do jovem bruxo Harry Potter, que tem a escola como cenário principal. Aliás, pode-se dizer que essas histórias obtiveram o maior sucesso de vendas de livros infanto-juvenis dos últimos tempos, pois, além de terem sido traduzidas para 63 idiomas, já foram vendidos cerca de quatrocentos milhões de exemplares dos sete livros da série em todo o mundo ${ }^{5}$.

Mas, além disso, essas obras se disseminaram em uma intricada rede de produções culturais, propagação que não foi interrompida nem mesmo após o lançamento do último livro, no ano de 2007. Argumento, então, a partir de tais indicações, que, mesmo nesses tempos pós-modernos, a escola segue sendo uma importante referência para os sujeitos ocidentais, quer seja ela vista como um local que deva primar por uma rentável qualidade e excelência, como postulam algumas propostas neoliberais, quer como um local de reprodução de ideologias e culturas dominantes e que, por isso, precisaria ser reestruturado, como indicaram educadores e sociólogos marxistas, especialmente nos anos 1970.

Saliento que a importância de proceder-se a uma análise da escola a partir das histórias sobre Potter decorre, especialmente, da inspiração buscada na vertente dos Estudos Culturais, pois nesses estudos ganha importância atentar para os efeitos produtivos das produções e instituições culturais. Assumindo essa perspectiva, em texto anterior (WORTMANN, 2009), vali-me da metáfora da teia para destacar como a literatura sobre Potter vem sendo conectada a diferentes produtos e artefatos, pois numerosos são os objetos disponibilizados ao consumo de seus/suas fãs. Entre esses estão varinhas de condão, capas, jogos de cama, bonés, agendas entre muitos outros. Mas, também, são numerosos os games, sites, chats, blogs, fanfictions, fanvideos entre outros espaços da internet em alguns dos 
quais, inclusive, novas histórias dão sequência ou reescrevem as histórias de Rowling, sob outros focos. Tais espaços da web congregam e permitem a comunicação de seus/suas fãs, sendo interessante indicar que, em 2007, ano de lançamento do sétimo e último livro da série, podia-se encontrar no site Google 160 milhões de referências a Potter, em todas as línguas possíveis (Pesquisa FAPESP, maio de 2007). Já no Orkut, site de relacionamento mais popular do Brasil, há cerca de 325.000 comunidades de fãs do pequeno bruxo (consulta realizada em 20 de julho de 2009). Além disso, os primeiros seis livros da série foram transformados em filmes de grande sucesso e muitos estudos acadêmicos também focalizam tais histórias. Portanto, seus efeitos produtivos vão bem além do entretenimento dos nem sempre jovens leitores/as consumidores/as dos diferenciados textos e artefatos que nela tiveram origem! Nessa rede de produções e representações disseminadas a partir das histórias sobre Potter, instituem-se e são colocados em circulação significados para muitas instituições contemporâneas, estando entre essas a escola, bem como para os/as sujeitos que nela atuam com maior destaque - os/as professores/as e estudantes. E, nesse sentido, é possível dizer, ainda, a partir dos estudos conduzidos por Shirley Steinberg (1997), Steinberg e Joe Kincheloe (2001), Douglas Kellner (2001), Henry Giroux e Peter McLaren (1995) e Giroux $(1995,2001)$, que tais produções operam como pedagogias culturais ${ }^{6}$ que, conectadas umas às outras, atuam para além da construção do seu sucesso mercadológico ou do otimismo com o chamamento dos/as jovens à leitura, como tem sido tantas vezes destacado: essas operam na produção de sujeitos e de suas compreensões de mundo.

Antes, porém, de passar a indicar alguns significados contemporâneos sobre a escola, aponto para colocações feitas por Roger Simon (1995) relativamente à noção de poder produtivo e ao modo como esse se vincula às práticas de produção semiótica por terem sido essas noções consideradas nas análises que apresento. Como refere esse autor (SIMON, 1995), tais práticas envolvem não apenas a criação de modos particulares de expressão simultânea, mas, também, as formas como tais significados são colocados no interior de sistemas de distribuição e exibição. Para Simon (1995), modos dominantes de produção semiótica atuam na normalização de práticas textuais e em repertórios de imagens que passam a ser configurados como verdadeiros ou úteis, ou, ainda, como aquilo que é condizente à sua adequada exibição e mediação. E é nesse sentido 
que tais práticas são simultaneamente educativas e políticas e que, ao examiná-las, podemos "aprender que a relação entre cultura e poder exige reconhecer que os modos particulares de produção semiótica não são arbitrários, mas histórica e economicamente constituídos pelas forças sociais no interior das quais vivemos nossas vidas" (SIMON, 1995, p. 64).

Outro aspecto a indicar foi enunciado por Barbero (2002a), ao salientar que as mais profundas modificações ocorridas nas sociedades contemporâneas podem ser associadas à circulação dos saberes possibilitada pela mídia. Como esse mesmo autor indicou, vivemos um tempo em que o ecossistema comunicativo encontra-se disperso e fragmentado e em que o saber passou a circular fora dos lugares sagrados que antes o detinham, além de ter-se afastado das figuras sociais que tradicionalmente o administravam. Ou seja, os saberes circulam, na contemporaneidade, por um número crescente de canais, não pedindo permissão à escola para expandirem-se socialmente, sendo, então, essa diversificação e difusão dos saberes fora da escola um dos aspectos mais importantes que o mundo da comunicação tem colocado ao sistema educativo nos dias de hoje. Invoco tal consideração, pois também a partir dela justifico meu interesse por examinar as configurações da escola no "mundo potteriano". Mas, antes de passar a destacá-las, retomo, brevemente, algumas posições enunciadas sobre o papel a ser cumprido pela escola por consagrados educadores brasileiros e por alguns importantes analistas culturais contemporâneos.

\section{Revisando (e destacando) algumas posições sobre o papel da escola}

Defensores do ideário escolanovista, bem como adeptos da pedagogia crítica, em suas múltiplas vertentes, colocaram em circulação no contexto educativo um grande número de propostas e de textos voltados a (re)definir o papel da escola. Enquanto na primeira tendência as propostas de modificação da escola voltaram-se especialmente à indicação de novas formas metodológicas a serem assumidas pelos/as professores/as, nas perspectivas críticas, uma das proposições mais destacadas salientou a importância de a escola prover todos os sujeitos da formação cultural e científica necessária ao exercício da cidadania. Ou seja, ao mesmo tempo que, nessa perspectiva, postula-se a necessidade de a escola conceder aos/às estudantes uma educação geral, capaz de fornecer-lhes 
conhecimentos específicos e de permitir-lhes desenvolver suas capacidades e habilidades intelectuais, nela destaca-se a importância de a escola voltar-se à formação de cidadãos capazes de participar ativa e conscientemente de todas as instâncias da vida social. Seria, então, nesse sentido, que se deveria reorganizar a escola, que viria mostrando ser bem pouco competente na execução de tais propósitos.

Como destacou o filósofo e educador crítico José Carlos Libâneo, em entrevista a Costa (2003), é importante pensar a escola como um espaço de síntese, síntese que incluiria "a cultura experienciada que ocorre na comunidade, na cidade, na rua, nas praças, nos pontos de encontro, nos meios de comunicação, na família, no trabalho, e aquela cultura formal que a escola representa" (COSTA, 2003, p. 25). Para esse autor, a democratização dos saberes requer da escola o provimento de condições cognitivas e afetivas que permitam ao aluno atribuir significados às mensagens e informações vindas dessa cultura experienciada, que seria fragmentada, lacunar e desordenada como um mosaico. Então, para Libâneo, o papel da escola seria auxiliar o aluno a reordenar e reestruturar essas informações, pois, como ele afirma: a informação domina, o conhecimento liberta, desde que saibamos dotar os alunos dos meios de pensar, dos meios de buscar informação, de modo que desenvolva suas capacidades de receber e integrar informação, mas também de produzi-la, de criar conhecimento, na condição de sujeito do próprio conhecimento (p. 25).

Mas esse não seria o único propósito a ser buscado pela escola na perspectiva crítica. Focalizando outras questões, e preocupado com a escola destinada às chamadas classes populares, o sociólogo e educador Miguel Arroyo, também em entrevista a Costa (2003), taxou de absurda e excessiva a fé depositada na escola para "mudar as coisas", propósito que, segundo ele, caracteriza o pensar político, social e pedagógico de muitos educadores brasileiros. Arroyo salienta que a escola segue sendo importante, não porque ela seja um passaporte, uma chave para tudo. Sua importância decorre de sermos "sujeitos de direitos e de termos direito ao conhecimento, ao saber, à formação, ao trabalho" (p.132), sendo essa a lógica em que se construiu, ao longo dos últimos séculos, a trajetória do “direito à educação básica”. Esse educador também destaca ser preciso discutir o significado dessa expressão, pois tal direito não implica, apenas, preparar os sujeitos para o trabalho, o que reduziria a concepção de direito e de ser humano a uma dimensão de mercadoria. Aliás, como o autor 
salientou, a universalização da educação básica se afirma no mundo muito mais como um movimento pela dignidade da infância e da adolescência do que em função de necessidades do mercado (COSTA, 2003, p. 136). Então, o que demandaria a necessidade da escola não seria apenas a lógica do mercado, mas sim a lógica da dignidade, que, cada vez mais, os sujeitos reivindicam para si e para seus filhos. A escola possível para este milênio dependerá, assim, segundo ele, dos paradoxos que o avanço dos direitos humanos virá a enfrentar, pois "quanto mais consciência o ser humano tiver de sua dignidade, de seus direitos e, sobretudo do direito a ser gente, mais necessária a escola será" (p. 151).

Já o curriculista britânico Ivor Goodson (2007) coloca em destaque a importância de os governos promoverem maior inclusão social na escola e de ela fornecer uma educação justa para todos, preocupação que, aliás, tem afetado o governo trabalhista inglês, que se debate com a insuficiência de escolas públicas, como indicou a articulista Clara Fagundes (2007), em reportagem publicada no jornal brasileiro Folha de S.Paulo. Goodson (2007) referiu ser difícil alcançar tais propósitos em função da existência de uma "gramática de escolarização", amplamente aceita, que toma como estabelecidos fenômenos educacionais como as disciplinas escolares tradicionais e os exames acadêmicos. O autor destaca que essa gramática tem sido vista como tão natural que mesmo os governos trabalhistas estenderam às State $S$ chools, escolas que atendem as classes trabalhadoras, padrões estipulados para as escolas da elite, as public schools. Invocando Bauman (2001), Goodson (2007) salienta que estudos bemdefinidos e prescritivos tornaram-se inadequados frente à nova ordem de trabalho flexível que se instalou na contemporaneidade. A inércia de tais currículos, afirma Goodson (2007), não resistirá às rápidas transformações dessa nova ordem do mundo globalizado e, sendo assim, o propósito de preparar para a vida - tarefa que o autor considera perene e invariável para qualquer tipo de educação - deverá passar a incluir o cultivo de habilidades que permitam viver-se o cotidiano em paz, apesar das incertezas e ambivalências dos diferentes pontos de vista e da ausência de uma autoridade infalível. O autor espera, então, que, em um novo futuro social, o currículo escolar se comprometa com as missões, paixões e propósitos nos quais as pessoas articulam suas vidas e que se substitua uma aprendizagem prescritiva autoritária e primária por uma aprendizagem narrativa e terciária, capaz de transformar as atuais instituições educacionais e de 
fazê-las cumprir sua antiga promessa de ajudar a mudar o futuro social de seus alunos.

Beatriz Sarlo (2002; 2003) tece seus comentários sobre a crise da escola considerando a importância que a cultura da mídia adquiriu na contemporaneidade. Ela se refere a uma escola pouco atraente, que oscilaria entre a aceitação benevolente e irrefletida do modismo da cultura juvenil e a sua crítica racional, às vezes, hipócrita. Para Sarlo (2003), a escola, quando comparada às produções midiáticas, pode ser vista como um lugar de pobreza simbólica ao qual os/as alunos/as das classes populares ainda vão por não disporem de alternativa melhor. Tal como Arroyo (2003), Sarlo (2002) chama a atenção para o perigo de voltar-se a escola à preparação para o trabalho, objetivo que reforçaria ainda mais as desigualdades sociais e culturais. A autora considera, ainda, que direcionar a escola ao ensinar a aprender, tal como postulava o ideário escolanovista, ou ao propósito muitas vezes simplificado na expressão estudar o que interessa aos jovens, suporia a possibilidade de existência de um autoabastecimento infantil que, igualmente, reforçaria as desigualdades socioculturais de origem e subordinaria a escola à cultura da mídia, transformando o ensino escolar em um simulacro pálido e demagógico da chamada cultura adolescente. Sarlo (2002) salienta que a escola até poderia aumentar sua eficiência ao valer-se de destrezas que seus alunos têm apreendido em outros espaços - a velocidade de feeling obtida a partir dos videogames; a capacidade de compreensão e resposta frente a uma superposição de mensagens nos videoclipes; e os conteúdos exóticos e familiares proporcionados pela mídia. No entanto, a importante pergunta que ela nos faz é se tais destrezas e saberes seriam suficientes para prover a aquisição de outros saberes e destrezas, tais como a argumentação, a escrita e a fluência linguística, que ela entende serem, até segunda ordem, necessárias ao mundo do trabalho e da política. Enfim, a autora defende a importância de a escola conceder aos/às estudantes uma cultura comum e comprometerse com um ideal democrático que precisaria ser reinventado em maior pluralismo, mas que não deveria ser descartado.

Tal como Sarlo (2002), Barbero (2002a; 2002b) também focaliza a escola considerando a intensa influência da cultura midiática. Ele destaca o quanto os/as alunos/as encontram-se impregnados de outras linguagens e saberes - na verdade, de fragmentos de saberes dos quais se apropriam a partir da mídia - e registra a incapacidade de o sistema escolar formar cidadãos capazes de lidar com os mapas profissionais e de trabalho 
que se avizinham. Para Barbero (2002b), necessitaríamos de uma escola capaz de usar, de forma criativa e crítica, os meios audiovisuais e as tecnologias informáticas e isso implicaria ensinar aos alunos/as a ler/decifrar um noticiário de TV com tanta desenvoltura quanto um texto literário. Para ele, necessitaríamos de uma escola em que o aprender a ler significasse também aprender a distinguir, valorizar e escolher entre juízos prévios e concepções renovadas de política, família, cultura e sexualidade. Mas, para tanto, a escola precisaria alterar o seu modelo e a sua práxis de comunicação. Ou seja, ela precisaria permitir que seus/suas alunos/as transitassem de um modelo centrado na sequência linear - que encadeia graus, idades e pacotes de conhecimento - a um outro, descentrado e plural, cuja chave seria o encontro do palimpsesto e do hipertexto. Apenas operando transformações nessa direção a escola poderia passar a interatuar com as novas formas de participação cidadã que esses novos ambientes da comunicação midiática lhe abrem contemporaneamente.

Já o curriculista carioca Antônio Flávio Barbosa Moreira comenta outro tipo de ação usualmente cobrado da escola - o que se refere ao atendimento à diversidade cultural. A preocupação de Moreira (2003, p. 66) segue na direção de pensar não que a escola possa dar conta da diversidade e da pluralidade dos muitos sujeitos e grupos - os portadores de necessidades especiais, as crianças das classes trabalhadoras, os negros, os homossexuais, os grupos indígenas, entre outros -, como postulam de forma até aligeirada alguns pedagogos contemporâneos, mas que torne possível pensar sobre o que une tais grupos; enfim, sua proposição, aparentemente pouco ambiciosa, mas extremamente pertinente para esses tempos de tanta complexidade para a escola, sugere que se pense sobre alguma forma de solidariedade possível entre tais sujeitos, ou seja, que se pense algum projeto comum, ou de qualquer tipo de ação que torne possível o diálogo entre eles.

Ao concluir essa seção, é importante indicar que os/as autores/as citados/as, bem como os/as articulistas de jornal que foram referidos/as, denunciam a existência de uma crise que afeta a escola. E não apenas a escola organizada para as camadas marginalizadas, mas, também, a frequentada pelas camadas médias urbanas até por conta da importância alcançada pelas ações midiáticas. Também é importante destacar que muitas são as representações instituídas para a escola na contemporaneidade. Ela já foi representada como local de prepotência e arbitrarieda- 
de e denunciada por não ter conseguido transformar esse autoritarismo em autoridade, tal como indicou Sarlo (2003); além disso, padeceu males associados à idealização operada ora a partir de reminiscências guardadas na memória de alguns literatos, tais como os citados na seção introdutória deste texto, ora a partir dos arroubos associados a sonhos de mudança social e libertação, idealizados por pedagogos críticos, ora a partir da sua associação ao mercado, como postulam os adeptos do neoliberalismo, e ora, ainda, a partir de sonhadas possibilidades inclusivas.

Apontam-se, com frequência, novos e crescentes desafios para a escola e, ainda, o quanto ela carece de ideais a transmitir frente aos novos mapas culturais delineados nas sociedades contemporâneas. Como destacou Barbero (2002a), os/as jovens desenvolveram cognições e sensibilidades bastante desligadas das figuras, estilos e práticas das velhas tradições que definiam a cultura até meados dos anos 1960, assumindo sensibilidades pós-modernas que continuam, no entanto, articulando-se a sensibilidades modernas, mesmo que de forma efêmera. E é essa abertura a muitas e diferentes formas - a esses modos de viver camaleônicos no qual se experienciam identidades mais precárias e flexíveis -, como também destacou Barbero (2002a), que se constitui em um dos desafios mais importantes a serem enfrentados pela escola contemporânea.

\section{A escola que se (re)inscreve e ensina nas histórias sobre Harry Potter}

Passo, a seguir, a focalizar significados atribuídos à escola nas histórias sobre Harry Potter? . Começo destacando que praticamente não há críticas à escola na saga potteriana. Ao contrário, nos sete livros que narram as aventuras desse jovem bruxo, reafirma-se, constantemente, sua importância e excelência.

A escola delineada nesses livros configura-se como um local destinado à formação sistemática (em magia) de estudantes bruxos e bruxas, personagens dessas histórias, sendo que essa se faz sob a supervisão de seus professores e professoras - bruxos/as, fantasmas e até mesmo um lobisomem -, alguns/algumas brilhantes e competentes ${ }^{8}$, outros/as medíocres e até mal-intencionados ${ }^{9}$, tal como sucede nas escolas reais.

A escola configurada nesses livros é necessária à adequada formação da comunidade bruxa, que nela aprende as formas corretas e éti- 
cas de lidar com as artes da magia e que lá também se apropria dos saberes mágicos instituídos nas suas tradições, bem como dos códigos e das regras que devem reger ações na comunidade bruxa. Para tanto, os/as aprendizes de bruxos/as cursam um currículo integrado por disciplinas como Astronomia, Feitiços, Poções, Trato das Criaturas Mágicas, Herbologia, História da Magia, Artes das Trevas, Runas Antigas, Transfiguração e Adivinhação (livro 6, p. 82) e consultam necessariamente compêndios disponibilizados na enorme biblioteca da escola. E entre os títulos que lhes são indicados estão: Grandes sábios do século XX; Nomes notáveis da magia de nosso tempo; Importantes descobertas modernas da magia; Um estudo dos avanços recentes na magia; Teoria da magia; História da magia. Além desses, títulos como o Livro padrão de feitiços; o Guia de transfiguração para iniciantes; Transfiguração para o Curso Médio; Bebidas e poções mágicas; Animais fantásticos e seu habitat, As forças das trevas: um guia de auto-proteção; Mil ervas e fungos mágicos, entre outros, que podem ser encontrados na livraria da ficção, especializada em livros de magia, O Beco Diagonal.

A formação em magia exige, assim, além do comparecimento sistemático às aulas, a consulta constante à bibliografia do campo (a magia), destacando-se nessas histórias a importância que os livros têm para o encontro de soluções não apenas para as situações de sala de aula, geralmente narradas como exigentes e instigantes, mas, também, para os inúmeros segredos que a escola esconde e que os/as estudantes precisam desvendar para poderem viver mais ou menos tranquilamente em Hogwarts. Aliás, também está sugerido na série que as ações de sala de aula não os/as instrumentalizam explicitamente para tal empreitada. No entanto, essa é uma das poucas desconfianças que as histórias levantam sobre o papel do ensino ministrado em sala de aula, aspecto que, no entanto, parece ser remediado, como a narradora sugere, pelo convívio direto e instigante que os/as alunos/as têm com alguns/algumas dedica$\mathrm{dos} /$ as professores/as da escola. Mas as histórias salientam, também, que os/as jovens bruxos/as precisam aprender a manusear adequadamente os livros, pois há, na biblioteca de Hogwarts, livros que atacam e mordem os que pretendem lê-los, sendo necessário, portanto, aprender antes a manuseá-los para que isso não aconteça. Por outro lado, nela há livros aos quais os/as estudantes não podem ter acesso em função da natureza de seu conteúdo - o poderoso efeito das bruxarias que apresentam - ou que só devem ser consultados com a autorização prévia de algum/a professor/a. 
Então, tal como sucede nas escolas reais, procede-se, em Hogwarts, a sistematizações e interdições em relação ao que pode ser acessado e conhecido. E essas têm implicações no aprendizado de códigos e regras de conduta configurados como indispensáveis não apenas para que os/as alunos/as tenham uma passagem exitosa nesse internato, frequentado por jovens de ambos os sexos, mas, inclusive, para que eles/as possam sobreviver nesse ambiente escolar que esconde perigos insuspeitados.

Assim, todas as aprendizagens, sejam elas alcançadas nas aulas regulares, sejam obtidas a partir da iniciativa pessoal ou da troca interativa entre grupos de colegas amigos/as, ou, ainda, a partir de encontros não-formais entre professores/as e seus/suas alunos/as, são configuradas como extremamente importantes para a consecução de um objetivo comum: a preparação dos/as jovens aprendizes (de bruxarias) para viver na sociedade (bruxa) e, mais do que isso, sua capacitação para escapar dos inúmeros ardis e estratégias de cooptação que os agentes do mal vão executando para envolvê-los ou seduzi-los. E essa me parece ser uma das muitas formas constantes nessas narrativas de representarem-se os perigos que a vida real pode apresentar aos jovens que vivem a contemporaneidade, perigos esses que, com frequência, adentrariam os muros de nossas escolas.

Mas, voltando ao relato das aulas realizadas em Hogwarts, cabe ainda referir que as histórias registram serem inúmeras as atividades de caráter prático realizadas nas aulas regulares. Em Astronomia, por exemplo, os/as jovens bruxos/as aprendem a examinar o céu da meia-noite com o auxílio do telescópio para conhecerem as estrelas e os planetas; em Herbologia, as aulas ocorrem na estufa de plantas do castelo e nelas os/as estudantes aprendem a cuidar de todas as plantas e, em especial, de fungos estranhos e a descobrir seus efeitos, bem como as soluções em que todos esses vegetais podem ser usados; nas aulas de Feitiços e nas de Defesa Contras as Artes das Trevas preponderam atividades práticas, mas nelas se ensina, também, como utilizar adequadamente expressões mágicas e o modo de empunhar corretamente a varinha de condão, habilidades configuradas como necessárias ao bom exercício da magia. Já as aulas de História da Mágica, essencialmente teóricas, são indicadas como aquelas de que os/as jovens bruxos/as menos gostam, opinião que parece também ecoar nos corredores de muitas escolas reais e figurar como uma 
crítica frequente, notadamente entre educadores que se vinculam ao escolanovismo e que postulam a necessidade de um ensino que se caracterize pela preponderância das chamadas vivências práticas.

Então, é importante salientar que tanto a estrutura curricular dessa escola da ficção quanto as denominações dos compêndios, referidas nas histórias sobre Hogwarts, parodiam currículos escolares do mundo real e títulos de manuais e livros didáticos utilizados especialmente em escolas tradicionais, valorizadas, exatamente, por assumirem tal opção. Outro aspecto que situa essa escola de magia na categoria de escola tradicional e aristocrática são as suas dependências: Hogwarts é descrita como um lugar estupendo!

A escola localiza-se em um imenso castelo cheio de torres e torrinhas, encarrapitado no alto de um penhasco, à margem de um grande lago escuro e liso como um vidro, sendo acessada apenas por barco (Livro 1, p. 99). Seu imenso saguão destaca-se pelo piso de lajotas de pedra, pelas paredes iluminadas com archotes flamejantes, pelo teto muito alto e pela imponente escada que conduz aos andares superiores (Livro 1, p. 100), onde ficam as quatro diferentes casas em que se organizam a escola ${ }^{10} \mathrm{e}$ as salas de aula. Nela há, também, um grande salão, no qual se realiza o banquete de abertura do ano letivo. Nessa situação, ele é descrito pela narradora da história como iluminado por milhares de velas, estando nele dispostas mesas compridas cobertas com pratos e taças dourados e uma grande quantidade de comidas e sobremesas apetitosas.

O castelo possui 142 escadas, algumas largas e imponentes, outras estreitas e precárias, outras, ainda, com inúmeros obstáculos, quadros cujas figuras se movimentam e falam, e até saem das molduras, além de portas que só se abrem para os/as conhecedores de suas senhas, sendo esses mais alguns dos códigos que os/as estudantes devem conhecer para poderem circular, mesmo que não muito livremente, nessa escola. Mas, cabe registrar, novamente, que as descrições feitas da escola Hogwarts evocam, de muitas maneiras, elementos que a associam à tradição, à nobreza e à riqueza, aspectos usualmente invocados para caracterizar tradicionais escolas particulares, notadamente as inglesas. E também salientar que essas descrições mesclam o encanto e o mistério dos castelos narrados nas histórias infantis com elementos advindos da realidade, sendo que a combinação constante entre o mágico e inusitado e o real se repete na narração de muitas situações, estratégia que talvez explique, tal como 
indicou Isabelle Smadja (2004), pelo menos parcialmente, o grande interesse que essas histórias têm suscitado. Assim, muitas são as estratégias narrativas que vão atribuindo uma aura de magia e encantamento a essa escola de bruxos (e, por extensão, de certo modo, a todas as escolas), e esse delineamento passa, também, pela valorização da amplitude de saberes e de práticas a que a partir dela se pode ter acesso. Mas, é impossível deixar de comentar, o quanto as descrições de Hogwarts diferem das que narram as escolas públicas brasileiras!

Outro aspecto que é necessário registrar refere-se ao destaque dado, nessas histórias, às alterações processadas na vida de Potter desde o momento em que ele foi aceito como aluno em Hogwarts. Aliás, essa escola é definida pelo personagem Hagrid, um híbrido de bruxo/gigante e um leal defensor de Potter, "como a melhor escola de bruxos e bruxedos do mundo (...) local onde \{Potter\} estudará com garotos iguais a ele (Livro 1, p. 55). Em Hogwarts, Potter não apenas descobriu ser dotado de poderes e aptidões que não suspeitava possuir - ele descobriu ser um humano/bruxo detentor de poderes especiais -, como passou a ser respeitado e considerado, o que não sucedia em sua antiga escola (escolhida por seus tios por ser gratuita), na qual era constantemente espezinhado pelos amigos de seu primo Duda. Ao longo dos sete anos transcorridos em Hogwarts - cada um dos livros da série corresponde a um ano de vida escolar e pessoal do herói das histórias -, Potter vai descobrindo ser um predestinado. Ele percebe o importante papel que terá a cumprir junto à comunidade bruxa - lutar pela sobrevivência de todos/as aqueles/as alinhados/as às causas do bem, tal como fizeram anteriormente seus pais, seu padrinho (a misteriosa e injustiçada personagem Sirius Black), o diretor de Hogwarts, Alvo Dumbledore (um erudito, longevo e respeitado bruxo), bem como outros/as bruxos/as do bem, todos/as eles/elas ex-alunos/as de Hogwarts que foram sendo aniquilados/as pelas forças do mal ao longo da série.

E, ao mesmo tempo, o herói vai aprendendo a sobreviver frente a perigos que lhe exigem colocar constantemente à prova suas aptidões e aprendizagens, ações que lhe permitiram ir, gradativamente, descobrindo suas potencialidades, inquietações, fraquezas, temores e habilidades. Aliás, as histórias marcam, de diversas formas, que Potter está na escola para preparar-se adequadamente para o grande embate final (e este acontece no sétimo e último livro), no qual enfrentará lord Voldemort, Aquele- 
Que-não-Se-Deve-Nomear, personagem que sintetiza as mais poderosas forças maléficas que ameaçam a comunidade bruxa, e com quem o herói vai descobrindo ter algumas ligações que não deixam de inquietá-lo - por exemplo, a fênix que produziu a pena de sua varinha de condão produziu apenas uma outra pena, que está na varinha de lord Voldemort, tendo sido essa a varinha que produziu a cicatriz que Potter possui na testa e que lateja sempre que ocorre alguma investida das forças do mal.

Então é nessa escola, e nas aprendizagens que ela pode oferecer a esse herói, que se encerram todas as possibilidades de Potter ser bemsucedido nessa sua futura missão, tal como se almeja que suceda com os/as estudantes que cursam nossas escolas reais, conforme destaquei em seção anterior.

Hogwarts é também representada nas histórias como um local de acolhimento, no qual Potter encontrou solidariedade e bem-estar (e, especialmente, um quarto amplo que passou a dividir com colegas amigos, bem como uma cama espaçosa e com dossel) ${ }^{11}$, sendo a capacidade de acolhimento um atributo visto como fundamental à escola, por muitos/as de seus/suas críticos/as atuais. E, afinal, foi em Hogwarts que Potter encontrou seus/suas primeiros/as e leais amigos/as, todos/as bruxos/as como ele, bem como alguns/algumas de seus/suas protetores/as, além de descobrir ser admirado por muitos de seus pares. Lá, como a narrativa destaca, ele finalmente encontrou "os seus iguais" e isso lhe permitiu estar à vontade - na verdade a escola é o lugar onde o herói se sente feliz - e, nesse sentido, o enriquecimento que a escola trouxe à sua vida excedeu, sobejamente, a simples aquisição de alguns saberes peculiares e o acesso às tradições e ritos bruxos.

Assim, a partir do que as histórias registram, pode-se pensar que Hogwarts exerceu sobre o herói uma ação assemelhada à que se espera da escola nas perspectivas educacionais críticas - ela lhe permitiu descobrir a si mesmo, bem como reconstruir sua história, além de ter-lhe permitido alcançar aprendizagens úteis para operar transformações na sociedade (bruxa). A escola Hogwarts propiciou-lhe inúmeras descobertas: lá ele aprendeu a ser aluno/a bruxo/a, sendo esse um aprendizado difícil! Além disso, descobriu que tal aprendizado não pode ser realizado por qualquer pessoa, pois, como as histórias marcam, para poder-se ingressar em Hogwarts é necessário possuir uma predisposição e um especial talento ser um mago! Todos/as aqueles/as que possuem aptidões para a magia 
(ao que parece, quando nasce um/a bruxo/a, tal acontecimento é imediatamente registrado na sociedade bruxa, mesmo que as histórias não esclareçam como isso se dá), no momento de sua chegada à escola são examinados por um artefato mágico - o chapéu seletor - que, ao ser colocado na cabeça do/a ingressante, lê sua mente e diagnostica em qual das casas o/a estudante deverá ser localizado/a, em função de sua personalidade e aptidões particulares. Desse modo, as histórias registram que nem todos os/as magos/as são enquadráveis em uma única categoria de mago, sendo que, para diferentes magos, há diferentes casas de acolhimento: Grifinória cultua valores como integridade e coragem; Corvinal, inteligência e beleza; Sonserina valoriza a ancestralidade bruxa e a ambição; e, Lufa-lufa, a lealdade e a honestidade. $\mathrm{E}$ as histórias conferem total credibilidade a esse processo seletivo, que se assemelha a algumas práticas valorizadas ora para definir a entrada dos estudantes em algumas escolas reais, ora para diagnosticar suas dificuldades - os testes psicológicos de aptidão mental que ainda gozam de tanto prestígio em muitas escolas e que são utilizados com bastante convicção em processos de seleção empresarial.

As histórias registram igualmente que o talento para a magia só será mobilizado por aqueles que frequentarem Hogwarts; ou seja, nelas se afirma reiteradamente que é a escola que habilita e transforma os sujeitos que nela ingressam (em magos). Aliás, está registrado nessas histórias que todos os sujeitos que foram alijados de Hogwarts passaram a ocupar posições marginais na sociedade (bruxa) - Hagrid ${ }^{12}$ e o agente de disciplina e zelador do castelo Filch ${ }^{13}$ são exemplos disso -, o que, mais uma vez, reitera a importância e a confiança atribuída à ação da escola nessa literatura.

Então, em representações como essas, (re)afirma-se nesses livros infanto-juvenis a crença no poder transformador da escola. Aliás, incumbir a escola desse tipo de responsabilidade, que implica atribuir-lhe a tarefa de preparar os sujeitos para a vida, é um propósito postulado e enfatizado por várias teorias educacionais, entre as quais figuram, tal como já indiquei anteriormente, as teorias críticas e o movimento pela Escola Nova. Mas, cabe ainda destacar que a referida escola não está configurada, apenas, como um reduto de bruxos do bem; ao contrário, há nela uma constante tensão entre os praticantes de ações do bem e os de ações malévolas, pairando, inclusive nos relatos, especialmente a partir do segundo livro da série, um clima de desconfiança e incerteza em relação às opções de alguns personagens frente a essa dualidade. São invocados nesse jogo nar- 
rativo, e isso também ocorre quando se narram algumas escolas reais, compromissos ancestrais, bem como preconceitos que alimentam as muitas disputas de poder que permeiam as histórias, sendo a mais importante delas a que se refere à pureza das linhagens (bruxas). Ao longo da saga, tal aspecto opõe cada vez mais intensamente bruxos puros e não-puros ${ }^{14}$, tornando os antagonismos motivados por essa diferença genética um dos aspectos mais destacados nessas histórias. Ou seja, em Hogwarts e nas sociedades bruxas há, também, discriminações e preconceitos, tal como sucede nas escolas e nas sociedades reais, sendo esse o foco que mobiliza o engajamento dos/as estudantes e professores/as que se alinham às práticas do bem. Mas é interessante referir que os/às estudantes de Hogwarts narrados nessas histórias acatam de forma até surpreendente seus regulamentos, mesmo que Potter e seus amigos e amigas valham-se, muitas vezes, de artefatos mágicos (entre esses a capa da invisibilidade) para transgredir certas regras e normas escolares.

No entanto, tais procedimentos são justificados na narrativa por serem esses demandados por causas legítimas, que implicam a segurança de personagens da história dos já referidos perigos que pairam na escola. É interessante registrar, no entanto, que mesmo os/as alunos/as que se filiam às correntes do mal, nunca afrontam seus professores e professoras, apesar de alguns/algumas professores/as assumirem posições autoritárias e até agressivas frente a ações dos/as escolares. Aliás, cabe indicar que tais estudantes diferem bastante dos narrados em análises educacionais como as conduzidas por Margulis e Urresti (2000), Fraga e Iulianelli (2003), Duschatski e Corea (2006), tal como destacaram Wortmann; Pires; Zoppas (2007). Em tais textos, fala-se de uma juventude pobre, questionadora, rebelde e até delinquente, que tem problemas de adaptação à escola e à sociedade. Problemas dessas ordens não são sequer mencionados nas histórias de Rowling, sendo possível dizer que os/as estudantes de Hogwarts aproximam-se bem mais dos que foram enquadrados por Fraga e Iulianelli (2003) na categoria bom-mocismo - eles são obedientes e disciplinados -, mesmo quando mobilizados pelos agentes do mal. Aliás, como destacou o analista cultural britânico Andrew Blake (2006), a narrativa de Rowling sobre Potter nos remete a tradicionais histórias sobre escolas privadas inglesas, que são, ainda, nos dias atuais, segundo esse autor, muito populares na Grã-Bretanha ${ }^{15}$. Como Blake (2006) registra, nos anos 1990, os livros ingleses endereçados às crianças focalizavam, 
especialmente, uma realidade que o autor qualificou como desconfortável, pois nelas predominavam temas como pobreza, gravidez na adolescência e dependência de drogas.

Para o autor, um crítico mordaz da sociedade bretã, apesar de esses serem temas politicamente corretos, eles não motivavam os/as estudantes e, neste momento, surgiram as histórias sobre Potter, que acertaram em cheio no alvo, mobilizando estudantes de diferentes grupos sociais. E essa também pode ser vista como uma das muitas possibilidades capazes de explicar o estrondoso sucesso alcançado por esses livros.

\section{Algumas considerações finais}

Ao encaminhar este texto à sua finalização, é interessante ressaltar, novamente, a forma até surpreendente como as histórias narradas por Rowling consagram a instituição escola, bem como outras organizações e instituições das sociedades ocidentais contemporâneas, tais como a mídia, em tempos em que essas têm sido tantas vezes questionadas relativamente aos seus papéis. Aliás, há críticas bem-humoradas ao papel da mídia nessas histórias, que relatam um mundo da magia que se estrutura de modo muito semelhante ao chamado mundo real. O mundo da magia é também atravessado pelo consumo, tal como está referido de forma jocosa no livro $6^{16}$, no qual ocorre o acirramento das lutas entre as facções de bruxos do bem e do mal e a intensificação da comercialização de artefatos variados para proteção - medalhas metamórficas, que permitem assumir mil disfarces, novos modelos de vassouras voadoras, poções protetoras, instruções para o uso de feitiços defensivos (livro 6, p. 72). Ou seja, como as histórias destacam, há, no mundo da magia, sujeitos que se aproveitam do temor de alguns para dele auferir lucros e há também representações de como a mídia se ocupa e lida com os momentos de crise vividos nas sociedades inscritas, por exemplo, na figura da personagem repórter sensacionalista Rita Skeeter, que dá destaque a notícias alarmantes (e parcialmente verdadeiras) para incrementar as vendas de seu jornal e até para servir às forças do mal.

Mas, em relação à escola, está destacada, já no primeiro livro da série, a importância atribuída à formação dos/as jovens (bruxos/as). Entre as muitas situações em que isso se processa, uma das mais signifi- 
cativas é aquela em que, reunidos/as na solenidade oficial de abertura do ano letivo, professores/as e alunos/as entoam entusiasmados/as o Hino da escola, cuja letra reproduzo a seguir.

\author{
Hogwarts, Hogwarts, Hoggy Warty Hogwarts, \\ Nos ensine algo por favor, \\ Quer sejamos velhos e calvos, \\ Quer moços de pernas raladas, \\ Temos as cabeças precisadas \\ De idéias interessantes \\ Pois estão ocas e cheias de ar, \\ Moscas mortas e fios de cotão. \\ Nos ensine o que vale a pena \\ Faça lembrar o que já esquecemos \\ Faça o melhor, faremos o resto, \\ Estudaremos até o cérebro se desmanchar (Livro 1, p. 113).
}

Como fica indicado na letra desse "Hino", atribui-se à escola a função de "encher as cabeças dos/as jovens de saberes". E o interessante é que a narrativa enfatiza serem os/as estudantes que clamam por isso, ao entoarem a letra do Hino. Mas, uma representação surpreendente acionada nessas histórias é a que configura a escola Hogwarts como um local que oferece perigos potenciais aos/às estudantes e professores/as que lá atuam. Interessante é, também, que tais perigos geralmente não chegam "de fora", pois, no caso dessa escola da ficção, eles decorrem, especialmente, dos segredos ancestrais que nela estão ocultos: há locais secretos em Hogwarts que escondem poderosos símbolos mágicos, capazes de servir tanto à redenção quando à destruição da comunidade bruxa ${ }^{17}$, dependo daquele/a que a esses venha a ter acesso. Por certo, não deixa de ser peculiar atribuir à escola o papel de depositária de tão importantes segredos, função da qual decorreu tornar-se ela um local de resistência e de lutas, especialmente no sétimo e último livro da série ${ }^{18}$. Aliás, nesse livro, a sociedade bruxa encontra-se literalmente em guerra, situação que impede o funcionamento normal da escola. E é então, neste momento, que a escola passa a ser a sede das forças do bem, local no qual Potter, seus amigos e amigas leais, bem como professores/as alinhados a essa causa, lutam contra as investidas dos Comensais da Morte ${ }^{19}$, de lord Voldemort e de seus/suas demais aliados/as, infiltrados na escola, que procuram destruir o jovem herói e assumir o controle da sociedade bruxa. E essa é, em meu 
ponto de vista, a representação mais positiva de escola posta em circulação nessas histórias - afinal, entre todas as instâncias da sociedade (bruxa), a escola foi a escolhida como o local que representa $o$ último reduto das forças do bem, nesses tempos em que, como destaquei na seção anterior, tantas críticas têm sido a ela proferidas!

Argumento, neste texto, que as muitas representações de escola colocadas em circulação nessas histórias não configuram, apenas, essas escolas da magia, mas se estendem às escolas reais contemporâneas. No entanto, não deixa de ser instigante constatar que o modelo de escola configurado como capaz de atuar tão eficientemente no processo formativo dos/as jovens (bruxos) se aproxime intensamente da abordagem curricular que Tomaz Tadeu Silva (2000) qualificou, ao discutir algumas perspectivas curriculares contemporâneas, como tradicional com enfoque bumanista clássico. Também surpreende que as disciplinas que integram a programação de Hogwarts arremedem as que Goodson (2007) considera como acadêmicas com alto status nas programações mais tradicionais e que se tome como padrão a rígida gramática de escolarização, também referida por Goodson (2007), à qual muitas escolas reais têm-se atrelado, independentemente da natureza ideológica das proposições que as inspiram.

Por tudo isso, é importante indicar que, nessas histórias infantojuvenis, a escola representa bem mais do que um pano de fundo para o desenvolvimento das aventuras narradas, tal como sucede em outras histórias desse gênero. Por certo, as representações forjadas e veiculadas nessas tão bem-sucedidas histórias denotam alguns dos significados atribuídos à escola na cultura contemporânea, como indiquei ao longo deste texto, mas elas também (re)configuram discursivamente um modelo de escola ainda bastante valorizado e defendido, independentemente das muitas críticas que sua adoção tem recebido. Não é que se esperasse encontrar em histórias infanto-juvenis alusão a discussões mais acadêmicas ou até críticas à insuficiência das instituições escolares contemporâneas, tal como sucede com frequência na mídia. No entanto, não deixa de surpreender a consagração que essas histórias fazem de uma organização escolar tão tradicional, que nelas se hibridiza com a escola pensada nas perspectivas críticas relativamente a seus propósitos. Alerto, no entanto, que não se está considerando que essas histórias tenham prestado um desserviço à escola, mas sim indicando o destaque positivo que esse modelo tradicional de escola nelas recebeu, aspecto que ganha importância ao 
considerar-se a intensa circulação que essa saga (e todas as produções que dela derivaram) tem tido nestes últimos dez anos.

Como muitas análises culturais destacam, não apenas as produções classificadas a priori como pedagógicas exercem efeitos produtivos sobre epistemes e sujeitos. Como indiquei nas seções iniciais deste texto, há uma variada gama de representações sobre a escola em circulação, em uma extensa e também diversificada lista de produções culturais. Como argumentei, elas podem exercer efeitos discursivos importantes sobre os modos de representar-se a escola. Mas ver a escola sob a ótica da magia, ou como propiciadora da emergência da magia, implica, certamente, conferir-lhe conotação bastante especial, sendo essa uma peculiaridade encontrada nesses livros de histórias infanto-juvenis, que mesclam de forma tão competente elementos retirados da vida social contemporânea, dos mitos, das lendas e das tradicionais histórias infantis.

Como se afirma nessas histórias sobre Harry Potter, é indispensável frequentar a escola (Hogwarts) para se tornar um/a cidadão/ã (mago/a) competente! E ao fazer-se tal afirmação não se deixa de atribuir a todas as escolas essa mesma competência, que envolve, neste caso, uma dimensão mágica que estava ausente das configurações da escola já há bastante tempo. 


\section{Referências}

ARROYO, Miguel. A escola é importantíssima na lógica do direito à educação básica (Entrevista). In: COSTA, Marisa Vorraber. A escola tem futuro? Rio de Janeiro: DP\&A, 2003.

BARBERO, Jesús Martín. Jovens: comunicación y identidad. Pensar Iberoamérica. OEI, N. 0 , febrero de 2002a.

BARBERO, Jesús Martín. La educación desde la comunicación. Barcelona: Editorial Norma, 2002b.

BLAKE, Andrew. A irresistivel ascensão de Harry Potter. Lisboa: Campo da Comunicação, 2006.

CAMUS, Albert. O primeiro homem. Rio de Janeiro: Nova Fronteira, 1994.

COSTA, Marisa Vorraber. Apresentação. A escola tem futuro? Rio de Janeiro; DP\&A, 2003.

DUSCHATZKI, Sílvia; COREA, Cristina. Chicos en bandas. Los caminos de la subjetividad en el declive de las instituciones. Buenos Aires: Paidós, 2006.

FAGUNDES, Clara. Reino Unido expande sua rede de ensino público. Folha de S.Paulo, 21 de outubro de 2007. (Caderno A, p. 24)

FRAGA, Paulo César Pontes; IULIANELLI, Jorge Atílio Silva (Orgs.). Jovens em tempo real. Rio de Janeiro: DP\&A, 2003.

GIROUX, Henry; McLAREN, Peter. Por uma pedagogia crítica da representação. In: SILVA, T.T.; MOREIRA, Antônio Flávio (Orgs.) Territórios contestados: o currículo e os novos mapas políticos e culturais. Petrópolis: Vozes, 1995.

GIROUX, Henry. Memória e pedagogia no maravilhoso mundo da Disney. In: SILVA, Tomaz Tadeu da (Org.) Alienígenas na sala de aula. Petrópolis: Vozes, 1995.

GIROUX, Henry. Atos impuros. A prática política dos estudos culturais. Porto Alegre: ARTMEd, 2003.

GOODSON, Ivor. Currículo, narrativa e o futuro social. Revista Brasileira de Educação, v. 12, n. 35. maio/ago, 2007.

HALL, Stuart; DU GAY, Paul. Representation: cultural representations and signifying practices. London/Thousand Oaks/ New Delhi: Sage/Open University, 1997.

KELLNER, Douglas. A cultura da mídia. Bauru: EDUSC, 2001.

LIBÂNEO, José Carlos. A escola com que sonhamos é aquela que assegura a todos a formação cultural e científica para a vida pessoal, profissional e cidadã. (Entrevista). In: COSTA, Marisa Vorraber. A escola tem futuro? Rio de Janeiro; DP\&A, 2003.

MACHADO, Uirá. Essa escola formal não serve para educar ninguém. Folha de S.Paulo, 26 de novembro de 2007. (Caderno A, p. 16).

MARGULIS, Mario; URRESTI, Marcelo. La juventud es más que una palabra. In: MARGULIS, Mario (ed.). La juventud es más que una palabra. 2 ed. Buenos Aires: Biblos, 2000. MOREIRA, Antonio Flavio Barbosa. A escola poderia avançar um pouco no sentido de melhorar a dor de tanta gente. (entrevista). In: COSTA, Marisa Vorraber. A escola tem futuro? Rio de Janeiro; DP\&A, 2003.

NERUDA, Pablo. Confesso que vivi. 19 ed. Rio de Janeiro: Bertrand Brasil, 1974.

SAYÃO, Rosely. Qualquer coisa é melhor que a escola formal de hoje; pior não fica. Folha de S.Paulo. 30 de novembro de 2007. (Caderno Cotidiano. p. 4).

SARLO, Beatriz. Escolas. In: MOREIRA, Antônio Flávio Barbosa; GARCIA, Regina Leite (Orgs.) Currículo na contemporaneidade. Incertezas e desafios. São Paulo: Cortez, 2003. 
SARLO, Beatriz. La escuela en crisis. In: Tiempo presente. Notas sobre el cambio de una cultura. 3 ed. Buenos Aires: Siglo Veinteuno, 2002.

SMADJA, Isabelle. Harry Potter. As razões do sucesso. Rio de Janeiro: Contraponto, 2004.

STEINBERG, Shirley. Kindercultura: a construção da infância pelas grandes corporações. In: SILVA, Luiz Heron et al. (Orgs.) Identidade social e a construção do conbecimento. Porto Alegre: Prefeitura Municipal de Porto Alegre, 1997.

STEINBERG, Shirley; KINCHELOE, Joe. L. (Orgs.) Cultura infantil: a construção corporativa da infância. Rio de Janeiro: Civilização Brasileira, 2001.

SILVA, Tomaz Tadeu. Documentos de identidade. 2 ed. Belo Horizonte: Autêntica, 2000.

VARGAS LLOSA, Mário. A cidade e os cachorros. Rio de Janeiro: Objetiva, 2007.

VILELA, Milú. Ambiente integral. Folha de S.Paulo, 6 de julho de 2007. (Caderno A, p. 3).

VILELA, Milú. O presente dos nossos sonhos. Folha de S.Paulo, 24 de dezembro de 2008. (Caderno A, p. 3).

WORTMANN, Maria Lúcia Castagna A ciência e a tecnologia que se inscrevem na magia das histórias sobre Harry Potter. In: COENGA, Rosemar (Org.). Leitura e literatura infanto-Juvenil. Cuiabá: Carlini \& Caniato, 2010.

WORTMANN, Maria Lúcia Castagna; PIRES, Fabiana de Brito. Harry Potter - para além da magia e da bruxaria. In: COSTA, Marisa Vorraber. A educação na cultura da mídia e do consumo. Rio de Janeiro: Lamparina, 2009.

WORTMANN, Maria Lúcia Castagna; PIRES, Fabiana de Brito; ZOPPAS, Isabel Christina. Identidades de gênero nas narrativas (mágicas) sobre Harry Potter. $16^{\circ} \mathrm{CON}$ GRESSO DE LEITURA DO BRASIL. Anais do $16^{\circ}$ COLE. No mundo há muitas armadilhas é preciso quebrá-las. Campinas: UNICAMP, Julho de 2007 (CD-ROM).

\section{Livros analisados}

ROWLING, J. K. Harry Potter e a pedra filosofal. Rio de Janeiro: Rocco, 2000.

ROWLING, J. K. Harry Potter e a câmara secreta. Rio de Janeiro: Rocco, 2000.

ROWLING, J. K. Harry Potter e o prisioneiro de Azkaban, Rio de Janeiro: Rocco, 2000.

ROWLING, J. K. Harry Potter e o cálice de fogo. Rio de Janeiro: Rocco, 2002.

ROWLING, J. K. Harry Potter e a ordem da Fênix. Rio de Janeiro: Rocco, 2003.

ROWLING, J. K. Harry Potter e o enigma do Príncipe. Rio de Janeiro: Rocco, 2005.

ROWLING, J. K. Harry Potter e as relíquias da morte. Rio de Janeiro: Rocco, 2007. 


\section{Notas}

1 Ao referir um/a autor/a pela primeira vez sempre indicarei seu nome completo.

2 Este programa cômico foi exibido pela emissora Brasileira Rede Globo de 1990 a 2002.

3 Este programa cômico com formato bastante semelhante ao da A escolinha do professor Raimundo foi exibido de fevereiro de 1991 até 2001 e represado à tarde, na mesma emissora, ao longo do ano de 2003. (Fonte: Wikipédia: A Enciclopédia livre. Consulta em 25 de julho de 2009).

4 Albert Camus faleceu em 1960.

5 Fonte Wikipedia, a Enciclopédia livre da Web (consulta em 17 de julho de 2009).

6 Esclareço que a expressão pedagogia cultural foi enunciada por esses autores/as para salientar a ideia de que a educação ocorre em uma variedade de locais sociais, incluindo a escola, mas não se limitando a ela.

7 Registro que não procedo, neste texto, a nenhuma análise de caráter literário, como seria possível se focalizasse a fabulação. Vali-me, na condução das análises, da abordagem a que Stuart Hall (1997) se referiu como construcionista cultural da produção de significados. Nesta abordagem, como indicou o mesmo autor, as coisas não significam: seu significado é construído em sistemas representacionais.

8 O professor Severo Snape, por exemplo, é caracterizado como competente, "severo", carismático, misterioso e até aterrorizador. Também o mago Alvo Dumbledore, que dirige a escola Hogwarts ao longo dos cinco primeiros volumes da série, é apontado como extremamente sábio e erudito. Já Minerva MacGonagall, uma das professoras da escola, é descrita como extremamente justa e afetuosa, apesar de sua aparência rígida e fria.

9 Entre esses está o vaidoso e "gabola" professor Gilderoy Lockhart, autor de numerosos livros por ele utilizados em sua disciplina e que, ao longo da série, revela-se um impostor - ele inventara todas as situações mágicas que apontava ter resolvido em seus livros.

10 Há quatro casas em Hogwarts e elas se diferenciam a partir de tradições que cultuam. A narrativa refere terem sido seus fundadores os bruxos Gryffindor e Slytherin e as bruxas Hifflepuff e Ravenclaw, que, juntos, construíram o castelo, mas que, por terem divergido relativamente aos critérios do processo seletivo para ingresso na escola - a questão central correspondia ao ensino da magia ser apenas facultado às famílias bruxas -, resolveram diferenciá-la nessas casas, que receberam o nome de seus fundadores. $\mathrm{Na}$ tradução portuguesa (Brasil), elas receberam as denominações: Grifinória, Sonserina, Lufalufa e Corvinal (v. 2, p. 131).

$11 \mathrm{Na}$ casa de seus tios, ele dormia em um pequeno cubículo, um armário localizado embaixo da escada, sendo bastante desconsiderado.

12 Este personagem só cursou até o $3^{\circ}$ ano de Hogwarts, pois foi expulso da escola ao ser acusado injustamente de ter aberto a Câmara Secreta (um dos espaços mágicos localizados no interior da escola). Mas, depois de Dumbledore ter-se tornado diretor de Hogwarts, ele passou a ocupar as funções de guardião das chaves de Hogwarts, de guarda-caça da escola, tornando-se, posteriormente, professor da disciplina Trato das Criaturas Mágicas (livro 5). 
13 Descobre-se, ao longo das histórias, que esse agente disciplinar é um aborto (v. 2, p. 127), isto é, um sujeito que, apesar de nascido em família bruxa, não conseguiu desenvolver poderes mágicos. Descobre-se, também, que ele estuda magia por correspondência (em um curso para principiantes) por não preencher os requisitos para cursar Hogwarts - ter aptidões mágicas (v. 2, p. 112). Destaco o sarcasmo da autora em relação a essa modalidade de estudo!

14 Harry Potter é um bruxo não puro; ele é filho de pai de ascendência bruxa e a mãe (também bruxa) não descendia de linhagens bruxas. Sua leal amiga, a personagem Hermione Granger, é de origem não-bruxa, mas, mesmo assim, dotada de poderes bruxos.

$15 \mathrm{O}$ autor refere ser um clássico desse gênero a história intitulada Tom Brown no colégio, escrita por Thomas Hughes, em 1861.

16 Esse livro intitula-se Harry Potter e o enigma do Príncipe. Rio de Janeiro: Rocco, 2005.

17 Entre esses estão a pedra filosofal, o basilisco, guardado na câmara secreta, o cálice de fogo e as relíquias da morte referidos nos diferentes volumes da série.

18 Este livro intitula-se Harry Potter e as relíquias da morte. Rio de Janeiro: Rocco, 2007.

19 Estes são personagens leais a Voldemort, portanto, agentes do mal. Eles/as possuem, tatuada em seu braço esquerdo, a marca negra - um crânio com uma serpente saindo da boca -, que, ao ser tocada, permitea a eles saber o momento em que devem entrar em ação. Nos primeiros livros, grande parte desses bruxos do mal se encontra presa em Azkaban, mesmo que alguns/algumas deles/as tenham permanecido infiltrados/as, sob diversos disfarces, na sociedade bruxa.

Recebido: $14 / 04 / 2009$

Aprovado: 21/05/2010

Contato:

Universidade Luterana do Brasil

Programa de Pós-Graduação

Av. Farroupilha, 8001

Prédio 14, sala 217 - São Luís

Canoas - RS

CEP $92450-900$ 
